\title{
Collaborative Technology Assessments of Transient Field Processing and Additive Manufacturing Technologies as Applied to Gas Turbine Components
}

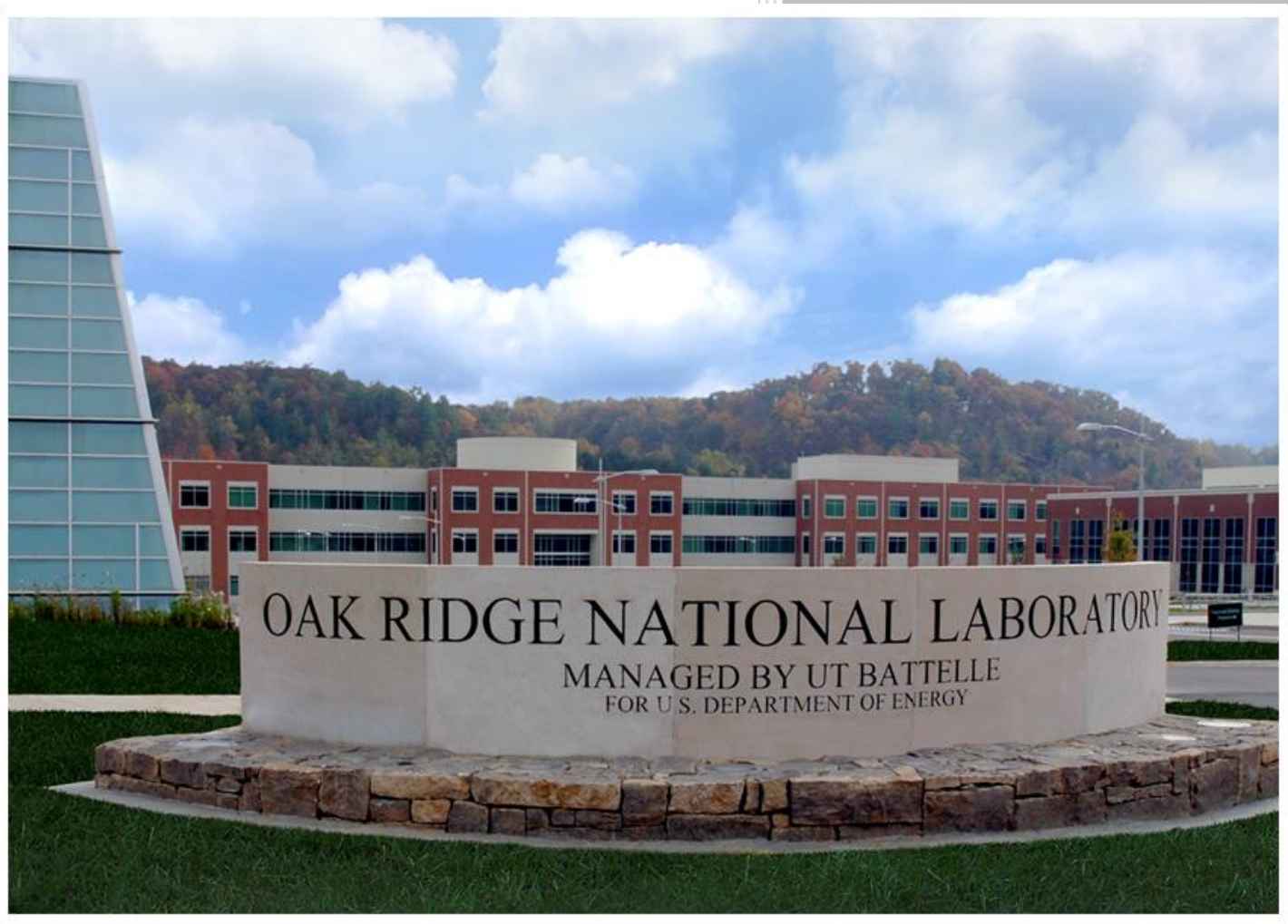

Gerard M. Ludtka Ryan R, Dehoff September 22, 2015

CRADA FINAL REPORT NFE-13-04453

Approved for Public Release. Distribution is Unlimited. 


\title{
DOCUMENT AVAILABILITY
}

Reports produced after January 1, 1996, are generally available free via US Department of Energy (DOE) SciTech Connect.

Website http://www.osti.gov/scitech/

Reports produced before January 1, 1996, may be purchased by members of the public from the following source:

\author{
National Technical Information Service \\ 5285 Port Royal Road \\ Springfield, VA 22161 \\ Telephone 703-605-6000 (1-800-553-6847) \\ TDD 703-487-4639 \\ Fax 703-605-6900 \\ E-mail info@ntis.gov \\ Website http://www.ntis.gov/help/ordermethods.aspx
}

Reports are available to DOE employees, DOE contractors, Energy Technology Data Exchange representatives, and International Nuclear Information System representatives from the following source:

Office of Scientific and Technical Information

PO Box 62

Oak Ridge, TN 37831

Telephone 865-576-8401

Fax 865-576-5728

E-mail reports@osti.gov

Website http://www.osti.gov/contact.html

This report was prepared as an account of work sponsored by an agency of the United States Government. Neither the United States Government nor any agency thereof, nor any of their employees, makes any warranty, express or implied, or assumes any legal liability or responsibility for the accuracy, completeness, or usefulness of any information, apparatus, product, or process disclosed, or represents that its use would not infringe privately owned rights. Reference herein to any specific commercial product, process, or service by trade name, trademark, manufacturer, or otherwise, does not necessarily constitute or imply its endorsement, recommendation, or favoring by the United States Government or any agency thereof. The views and opinions of authors expressed herein do not necessarily state or reflect those of the United States Government or any agency thereof. 
ORNL/TM-2015/565

CRADA/NFE-13-04453

Materials Science and Technology Division Advanced Manufacturing Office

\title{
COLLABORATIVE TECHNOLOGY ASSESSMENTS OF TRANSIENT FIELD PROCESSING AND ADDITIVE MANUFACTURING TECHNOLOGIES AS APPLIED TO GAS TURBINE COMPONENTS
}

\author{
Authors \\ Gerard M. Ludtka \\ Ryan R, Dehoff \\ Attila Szabo, General Electric Power and Water \\ Ibrahim Ucok, General Electric Power and Water
}

Date Published:

September 22, 2015

Prepared by

OAK RIDGE NATIONAL LABORATORY

Oak Ridge, Tennessee 37831-6283

managed by

UT-BATTELLE, LLC

for the

US DEPARTMENT OF ENERGY

under contract DE-AC05-00OR22725

Approved For Public Release 



\section{CONTENTS}

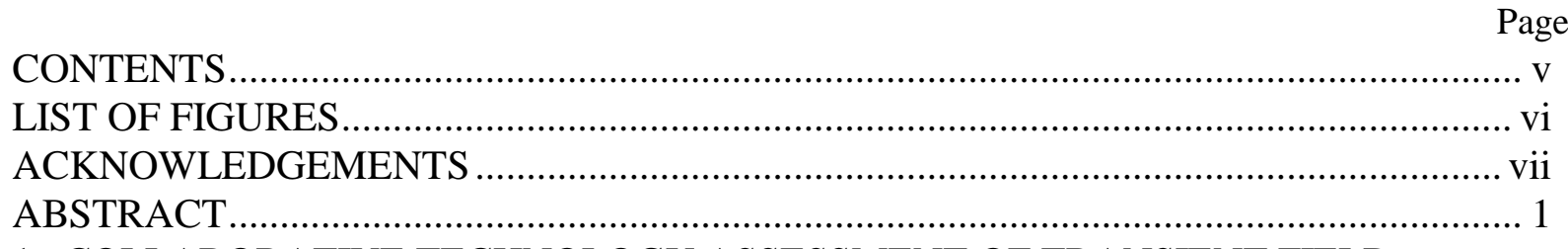

1. COLLABORATIVE TECHNOLOGY ASSESSMENT OF TRANSIENT FIELD PROCESSING AS APPLIED TO NOVEL LOWER COST NICKEL-IRON ALLOYS FOR USE IN HEAVY DUTY GAS TURBINE COMPONENTS …...................................... 1

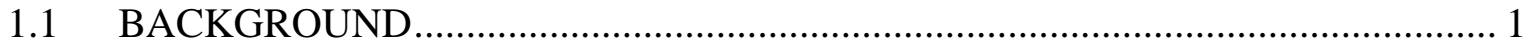

1.2 TECHNICAL RESULTS ....................................................................... 2

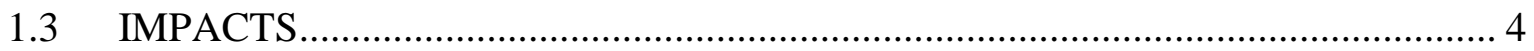

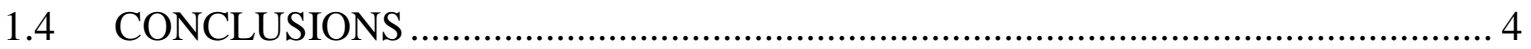

2. ADDITIVE MANUFACTURING FOR GAS TURBINE COMPONENTS ................... 6

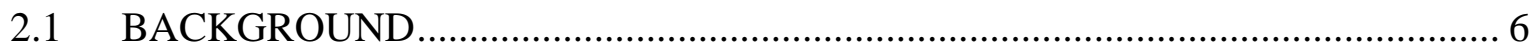

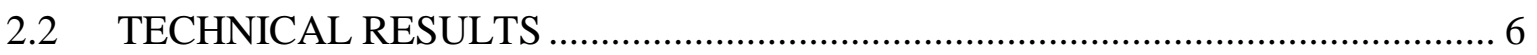

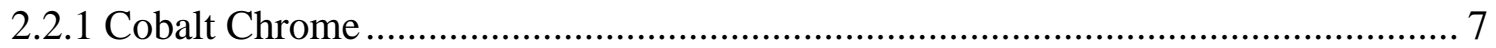

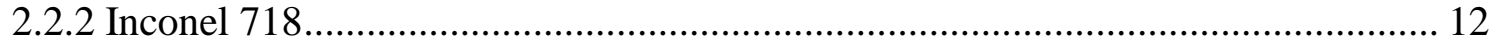

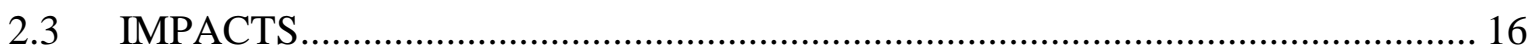

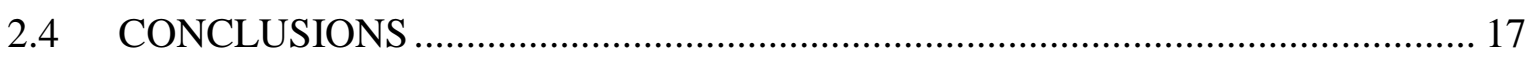

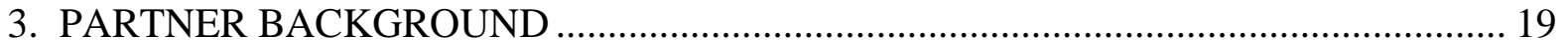




\section{LIST OF FIGURES}

Figure 1. Comparison of creep lives of Mod1, Mod2 and Mod3 samples after various HMFP.

Figure 2. Creep curves of (a) Mod2 samples subjected to various HMFP, and (b) Mod1

samples subjected to various HMFP......................................................................... 5

Figure 3. Creep curves of (a) Mod1, 2 and 3 samples double-aged without magnetic field, and

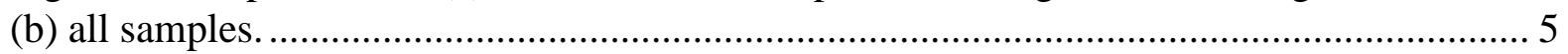

Figure 4. Horizontal LCF/tensile specimens built with EBM. ........................................... 7

Figure 5. Vertical LCF/tensile specimens built with EBM, with 0.1 " center holes built in. ... 8

Figure 6. Microstructure of EBM specimens as built. .................................................. 9

Figure 7. Microstructure of EBM specimens as built + stress relieved. ............................. 9

Figure 8. Microstructure of EBM specimens as built + stress relieved + HIP'ed................. 10

Figure 9. Microstructure of EBM specimens as built + stress relieved + HIP'ed + Solution +

Age.

Figure 10. Tensile test results of EBM specimens (stress relieved + HIP'ed + Solution +

Age) vs DMLM................................................................................................ 11

Figure 11. LCF test results of EBM specimens (stress relieved + HIP'ed + Solution + Age)

in 3 orientations. Test parameters were: $A=1, f=20 \mathrm{cpm}, \mathrm{R} / \mathrm{O}=100,000, \mathrm{~T}=1000 \mathrm{~F} \ldots 11$

Figure 12. Oxidation can be seen on both the outer surface as well as a cavity that was

exposed to the atmosphere during the HIP process. ..................................................... 12

Figure 13. Lines drawn on the boundaries of the inner and outer contours for Sample V2

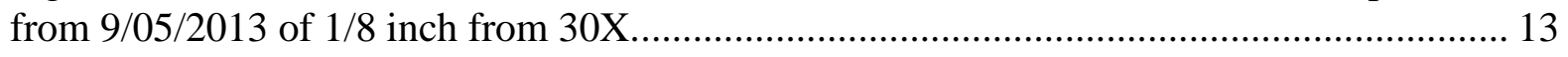

Figure 14. 1/32" Horizontal tensile test results.......................................................... 14

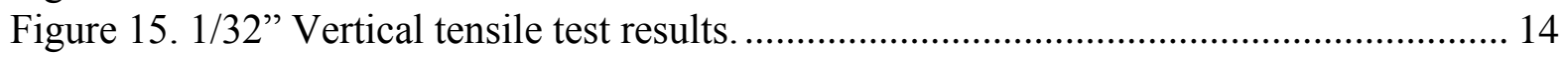

Figure 16. 1/16" Horizontal tensile test results............................................................. 14

Figure 17. 1/16" Vertical tensile test results. ................................................................... 14

Figure 18. 1/8" Horizontal tensile test results................................................................. 15

Figure 19. 1/8" Vertical tensile test results.................................................................. 15

Figure 20. Optical images of sample V2 from batch 2 of 1/8 inch from (a) 30X, (b) 100X, and (c) 200X. These images show interconnected porosity that was open to the surface during HIP and heat treatment..................................................................................... 15

Figure 21. Optical images of Sample H4 from batch 1 of 1/8 inch from (a) 20X, (b) 50X, and

(c) $100 \mathrm{X}$. Another example of interconnected porosity that was open to the surface........... 16 


\section{ACKNOWLEDGEMENTS}

This CRADA NFE-13-04453 was conducted as a Technical Collaboration project within the Oak Ridge National Laboratory (ORNL) Manufacturing Demonstration Facility (MDF) sponsored by the US Department of Energy Advanced Manufacturing Office (CPS Agreement Number 24761).

Opportunities for MDF technical collaborations are listed in the announcement "Manufacturing Demonstration Facility Technology Collaborations for US Manufacturers in Advanced Manufacturing and Materials Technologies" posted at http://web.ornl.gov/sci/manufacturing/docs/FBO-ORNL-MDF2013-2.pdf. The goal of technical collaborations is to engage industry partners to participate in shortterm, collaborative projects within the Manufacturing Demonstration Facility (MDF) to assess applicability and of new energy efficient manufacturing technologies. Research sponsored by the U.S. Department of Energy, Office of Energy Efficiency and Renewable Energy, Advanced Manufacturing Office, under contract DE-AC05-00OR22725 with UT-Battelle, LLC. 



\begin{abstract}
ORNL partnered with GE Power \& Water to investigate the effect of thermomagnetic processing on the microstructure and mechanical properties of GE Power \& Water newly developed wrought Ni$\mathrm{Fe}-\mathrm{Cr}$ alloys. Exploration of the effects of high magnetic field process during heat treatment of the alloys indicated conditions where applications of magnetic fields yields significant property improvements. The alloy aged using high magnetic field processing exhibited $3 \mathrm{HRC}$ higher hardness compared to the conventionally-aged alloy. The alloy annealed at $1785^{\circ} \mathrm{F}$ using high magnetic field processing demonstrated an average creep life 2.5 times longer than that of the conventionally heattreated alloy. Preliminary results show that high magnetic field processing can improve the mechanical properties of $\mathrm{Ni}-\mathrm{Fe}-\mathrm{Cr}$ alloys and potentially extend the life cycle of the gas turbine components such as nozzles leading to significant energy savings.
\end{abstract}

In the second part of this CARDA ORNL partnered with GE Power \& Water to investigate the use of additive manufacturing for complex turbine parts for high temperature application. The project successfully increased the build volume and range of materials that could be deposited using EBM for the gas turbine industry and identified the challenges to be overcome for full commercialization.

\title{
1. COLLABORATIVE TECHNOLOGY ASSESSMENT OF TRANSIENT FIELD PROCESSING AS APPLIED TO NOVEL LOWER COST NICKEL-IRON ALLOYS FOR USE IN HEAVY DUTY GAS TURBINE COMPONENTS
}

This phase 1 technical collaboration project (MDF-UP-2012-009) was begun on May 15, 2013 and was completed on August 31, 2014. The collaboration partner General Electric (GE) is a large business. ORNL partnered with GE Power \& Water to investigate the effect of thermomagnetic processing on the microstructure and mechanical properties of GE Power \& Water newly developed wrought Ni-Fe-Cr alloys. Exploration of the effects of high magnetic field process during heat treatment of the alloys indicated conditions where applications of magnetic fields yields significant property improvements. The alloy aged using high magnetic field processing exhibited 3 HRC higher hardness compared to the conventionally-aged alloy. The alloy annealed at $1785^{\circ} \mathrm{F}$ using high magnetic field processing demonstrated an average creep life 2.5 times longer than that of the conventionally heat-treated alloy. Preliminary results show that high magnetic field processing can improve the mechanical properties of $\mathrm{Ni}-\mathrm{Fe}-\mathrm{Cr}$ alloys and potentially extend the life cycle of the gas turbine components such as nozzles leading to significant energy savings.

\subsection{BACKGROUND}

GE Power \& Water is the world's leading supplier of industrial gas turbine engines, and has a demonstrated track record of developing and commercially implementing advanced materials technologies. The relevant Oak Ridge National Laboratory researchers are recognized as world class experts on materials development related commercialization, and energy impacts. Together, the project team combined their resources to rapidly develop transient metal processing technologies for GE Power \& Water developed new low cost gas turbine super alloy materials.

The team leveraged the pioneering ORNL work on carbon-, low-alloy and bainitic steels, and Fe$\mathrm{Ni}$ alloys under high magnetic field processing (HMFP) that demonstrated changes in solubility limits, 
phase equilibria, and kinetics that led to novel microstructure and mechanical properties in the corresponding materials. These changes led to reduction in processing times and steps and provided significant energy savings.

As a result of these achievements, a similar approach was taken by the ORNL and GE team for modifying microstructure and mechanical properties of $\mathrm{Ni}-\mathrm{Fe}-\mathrm{Cr}$ alloys newly developed by $\mathrm{GE}$ via HMFP.

GE's automated Materials Design Acceleration (MDA) technology enables multi-objective alloy composition modeling. It selects optimized alloys from thousands of alloy compositions based on predetermined critical to quality characteristics. Using this technology, GE has started to develop several promising low cost Ni-Fe-Cr alloys for gas turbine component applications. The goal of this project was to investigate potential performance improvements in creep life via HMFP of these alloys.

\subsection{TECHNICAL RESULTS}

To study the effects of HMFP on mechanical properties at various stages of heat treatment, three variations of a new proprietary GE Ni-Fe-Cr alloy (Mod1, Mod2 and Mod3), were subjected to HMFP using 9T magnetic field during (a) solution heat treatment (SHT) at $2000^{\circ} \mathrm{F}$, (b) double aging (DA) treatments at $1350^{\circ} \mathrm{F}$ and $1150^{\circ} \mathrm{F}$ or (c) annealing (Ann) at $1785^{\circ} \mathrm{F}$ (Table 1). HMFP samples along with conventionally heat treated samples were subjected to creep testing at $1400^{\circ} \mathrm{F} / 30 \mathrm{ksi}$. Processing conditions, and creep test results are given in Table 1.

As seen from Table 1 and Figure 1, the Mod2 sample that underwent annealing at $1785^{\circ} \mathrm{F}$ in 9Tmagnetic field exhibited the longest creep life among all tested samples. This sample also had a significantly longer life compared to other Mod2 samples, which were subjected to SHT under 9T magnetic field then DA and DA at 0T, respectively, see also Figure 2(a). This meant that annealing at $1785^{\circ} \mathrm{F}$ under magnetic field generated the best creep resistance by potentially influencing the microstructure through homogeneous grain growth, precipitate coarsening, or reducing grain boundary segregation. However, this hypothesis needs to be verified by further microstructure examination, and also by creep testing additional samples after annealing at $0 \mathrm{~T}$ which could be completed in a second phase of this project.

Figure 1 also showed that Mod1 samples, regardless whether HMFP applied, exhibited shorter creep lives compared to those of Mod2 and Mod3 samples, and there was not a significant difference between the creep lives (between $73 \mathrm{~h}$ and $100 \mathrm{~h}$ ) of the Mod1 samples, Figure 2(b). The behavior of Mod1 samples was attributed to their slightly different chemical composition compared to Mod2 and Mod3 and its different response to HMFP.

Upon double aging, Mod2 and Mod3 alloys exhibited similar creep lives which were significantly better than that of Mod1 per Figure 3(a). Note that Mod2 and Mod3 samples that underwent an aging heat treatment with or without HMFP, also exhibited similar creep lives between $364 \mathrm{~h}$ and $521 \mathrm{~h}$, Table 1. Mod2 sample that was solution heat treated under magnetic field and then double-aged exhibited the second best creep life (521h), indicating potential effect of HMFP. 
Table 1. List of creep sample conditions, and results of creep tests at $1400^{\circ} \mathrm{F} / 30 \mathrm{ksi}$.

\begin{tabular}{|c|c|c|c|c|c|c|c|c|}
\hline Sample & Alloy ${ }^{1}$ & SHT & DA & Ann & Condition $^{2}$ & $\begin{array}{l}\text { Rupture } \\
\text { Time (h) }\end{array}$ & $\begin{array}{l}\text { Rupture } \\
\text { Strain }(\%)\end{array}$ & Remarks \\
\hline 1 & MOD1 & $9 \mathrm{~T}$ & 9T & & $\begin{array}{l}\text { SHT@9T + } \\
\text { DA }\end{array}$ & 100 & 2.10 & $\begin{array}{l}7^{\text {th }} \text { best } \\
\text { creep life }\end{array}$ \\
\hline 2 & MOD2 & $9 \mathrm{~T}$ & $9 \mathrm{~T}$ & & $\begin{array}{l}\text { SHT@9T + } \\
\text { DA }\end{array}$ & 521 & 1.27 & $\begin{array}{l}2^{\text {nd }} \text { best } \\
\text { creep life }\end{array}$ \\
\hline 3 & MOD1 & & & OT & Ann@0T & 73 & 0.65 & $\begin{array}{l}\text { worst } \\
\text { creep life }\end{array}$ \\
\hline 4 & MOD2 & & & 9T & Ann@9T & 1685 & 2.70 & $\begin{array}{l}\text { best creep } \\
\text { life }\end{array}$ \\
\hline 5 & MOD1 & & $0 \mathrm{~T}$ & & DA@0T & 96 & 1.76 & $\begin{array}{l}8^{\text {th }} \text { best } \\
\text { creep life }\end{array}$ \\
\hline 6 & MOD2 & & $0 \mathrm{~T}$ & & DA@0T & 413 & 2.40 & $\begin{array}{l}4^{\text {th }} \text { best } \\
\text { creep life }\end{array}$ \\
\hline 7 & MOD3 & & 9T & & DA@9T-1 & 375 & 2.11 & $\begin{array}{l}5^{\text {th }} \text { best } \\
\text { creep life }\end{array}$ \\
\hline 8 & MOD3 & & OT & & DA@0T & 427 & 1.90 & $\begin{array}{l}3^{\text {rd }} \text { best } \\
\text { creep life }\end{array}$ \\
\hline 9 & MOD3 & & $9 \mathrm{~T}$ & & DA@9T-2 & 364 & 2.66 & $\begin{array}{l}6^{\text {th }} \text { best } \\
\text { creep life }\end{array}$ \\
\hline
\end{tabular}

${ }^{1}$ All samples were subjected to an initial heat treatment schedule consisting of solution heat treatment (SHT) at $2000^{\circ} \mathrm{F}$ followed by double-aging (DA) at $1350^{\circ} \mathrm{F}$ and $1150^{\circ} \mathrm{F}$. Anneal (Ann) was done at $1785^{\circ} \mathrm{F}$.

${ }^{2}$ The same SHT, DA, Ann. temperatures were used in HMFP trials at 9T and 0T magnetic field strength.

With rupture times between $364 \mathrm{~h}$ and $427 \mathrm{~h}$, creep behavior of three Mod3 samples, which were subjected to double-aging with or without HMFP, also appeared similar. This observation indicated that HMFP during aging treatments did not generate a microstructure change that could improve creep for this chemistry modification. Hardness measurements at room temperature, on the other hand, revealed an increased hardness by 3 HRC in the HMFP double-aged Mod 2 and Mod 3 samples. This meant that there was a potential microstructure change that needed further investigation. Effects of HMFP annealing at $1875^{\circ} \mathrm{F}$ on the wrought Mod3 samples also need to be explored because Mod3 samples, in the cast form, exhibited better creep performance compared to those of Mod1 and Mod2 samples during internal tests conducted by GE prior to the start of the project. 


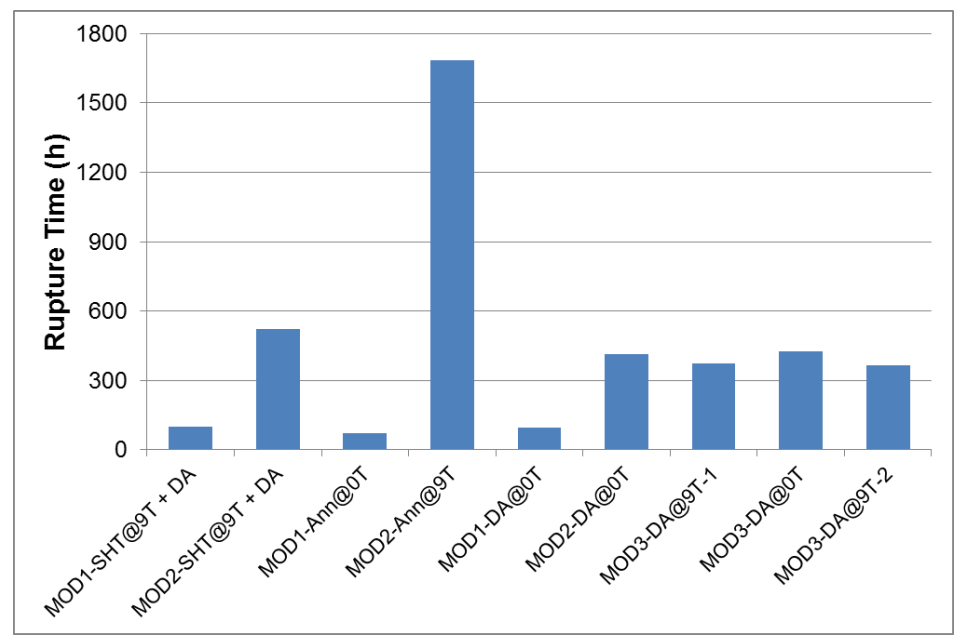

Figure 1. Comparison of creep lives of Mod1, Mod2 and Mod3 samples after various HMFP.

\subsection{IMPACTS}

In the low cost $\mathrm{Ni}-\mathrm{Fe}-\mathrm{Cr}$ alloys, iron displaces all of the cobalt and some nickel on a one-to-one basis in one current alloy grade, resulting in gas turbine components at nearly half the cost. HMFP of the patent pending new low cost Ni-Fe-Cr alloy has promising indicators that it can improve properties, reduce costs, reduce energy use, reduce pollution, improve product quality, and enhance productivity by modifying microstructure and properties which will accelerate the commercialization of these new alloys. GE and ORNL have filed a joint invention disclosure on this technology.

\subsection{CONCLUSIONS}

Wrought Ni-Fe-Cr alloy samples were subjected to various HMFP treatments. Samples subjected to HMFP during aging exhibited $3 \mathrm{HRC}$ higher hardness compared to the conventionally-aged alloy. The sample subjected to HMFP annealing at $1785^{\circ} \mathrm{F}$ exhibited the longest creep life, 2.5 times longer than that of the conventionally heat-treated sample, when tested at $1400^{\circ} \mathrm{F} / 30 \mathrm{ksi}$. The improvements were attributed to potential homogeneous grain growth, uniform precipitation, precipitate coarsening, and/or reduced grain boundary segregation Additional work is needed to identify the cause of the hardness increase upon HMFP-aging, and the reason for improved creep properties upon HMFPanneal. For this purpose, Mod3 Ni-Fe-Cr samples both in the cast and wrought forms may be HMFP'ed using a systematic approach in a second phase of this project. Microstructure and mechanical property evaluations may be made by optical microscopy, Scanning Electron Microscope (SEM), Orientation Image Mapping (OIM), and hardness and creep testing. 

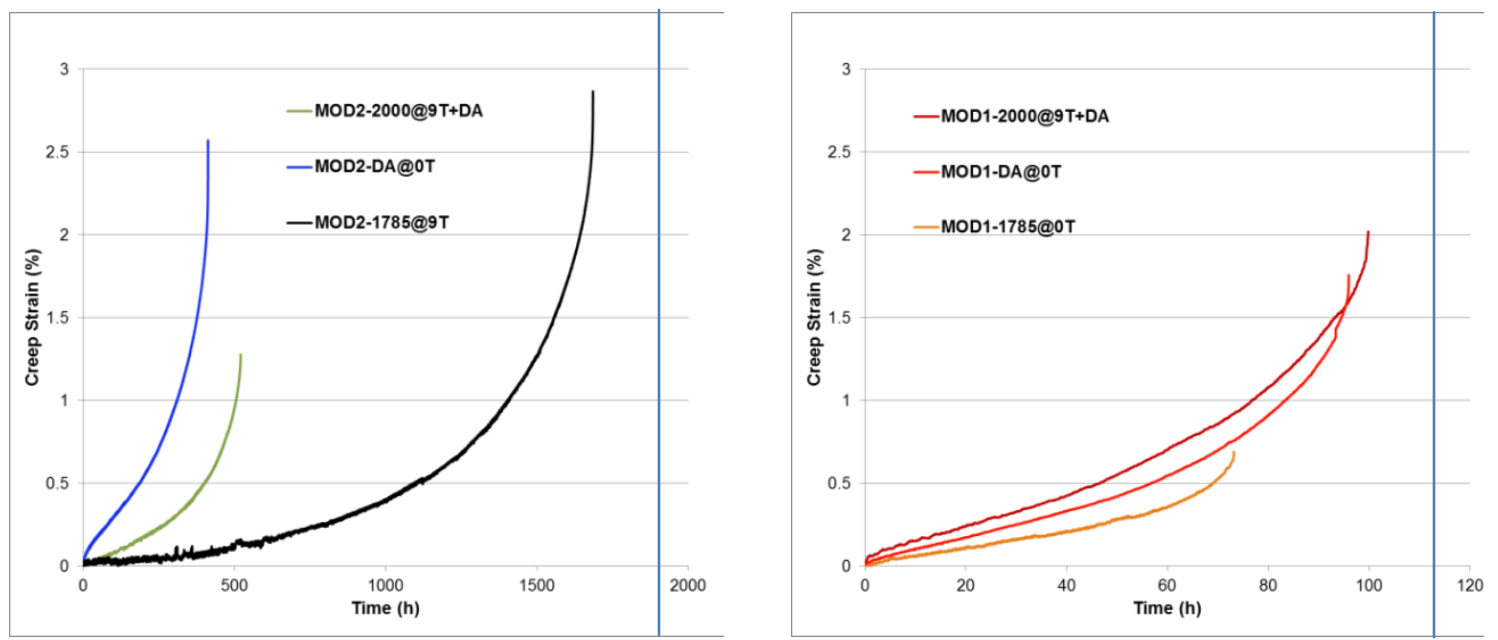

Figure 2. Creep curves of (a) Mod2 samples subjected to various HMFP, and (b) Mod1 samples subjected to various HMFP.
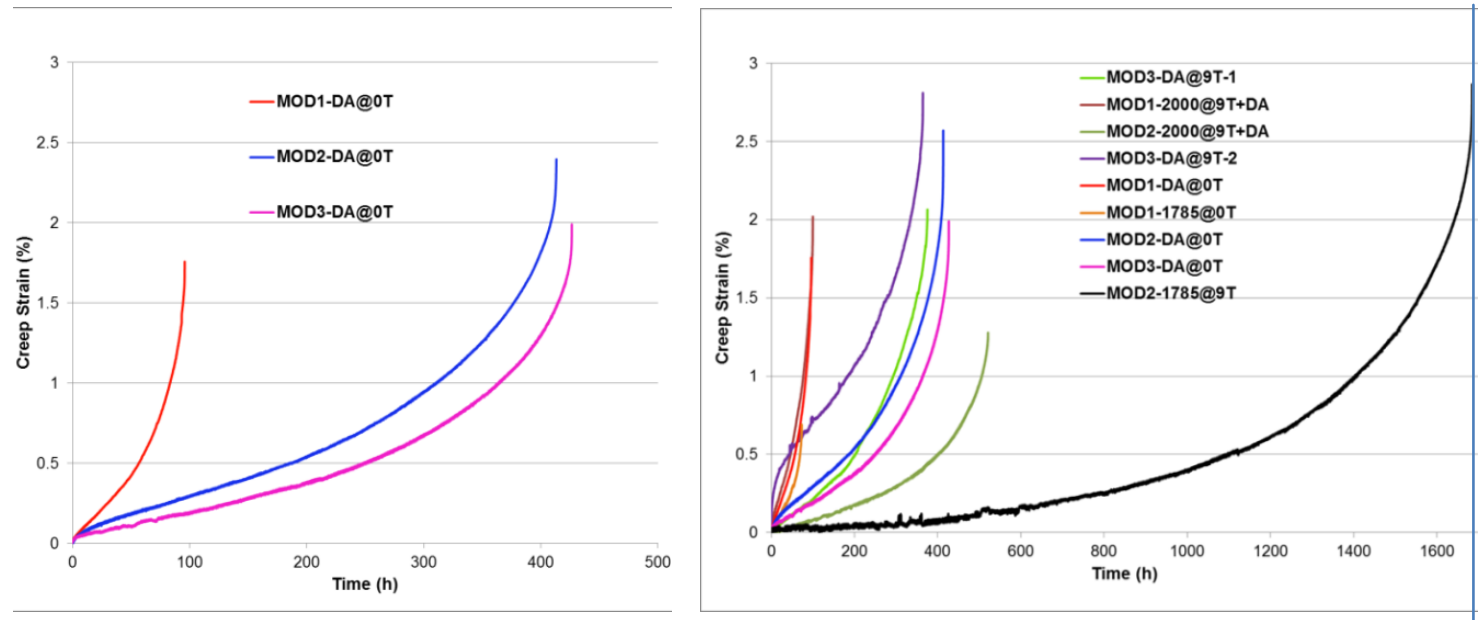

Figure 3. Creep curves of (a) Mod1, 2 and 3 samples double-aged without magnetic field, and (b) all samples. 


\section{ADDITIVE MANUFACTURING FOR GAS TURBINE COMPONENTS}

This phase 1 technical collaboration project (MDF-UP-2012-007) was begun on May 17, 2013 and was completed on April 30, 2014. The project successfully increased the build volume and range of materials that could be deposited using EBM for the gas turbine industry and identified the challenges to be overcome for full commercialization.

\subsection{BACKGROUND}

General Electric Power and Water is currently exploring additive manufacturing technologies to revolutionize the manufacturing process for complex assemblies and allow for improved designs for increasing the energy efficiency of industrial gas turbines. Much of the current focus on additive manufacturing is being conducted on cobalt chromium alloys fabricated using laser powder bed systems. One drawback associated with the laser deposition system includes relatively slow deposition rates in contrast to EBM. Although the EBM process may have a higher deposition rate, there are current challenges for the technology, including size of components that can be fabricated $(210 \mathrm{~mm} \mathrm{x}$ $210 \mathrm{~mm} \times 300 \mathrm{~mm}$ ), removing sintered but unfused powder materials for internally fabricated geometries, and a lack of materials utilized (currently Ti-6Al-4V, CP Ti, and CoCr). The goal of this project was to examine the EBM process as a possible method for manufacturing components for GE Power and Water, and identify challenges that must be overcome in order to implement this technology into production.

\subsection{TECHNICAL RESULTS}

ORNL demonstrated the ability to fabricate the first full-scale plenum for a General Electric (GE) land based turbine from cobalt-chrome $(\mathrm{CoCr})$ using the Arcam Electron Beam Melting (EBM) process. Prior to this technical collaboration, it was not possible to fabricate a full-scale plenum using EBM due to size limitations with the EBM process. In addition, the original design of the plenum would not allow for sintered powder to be removed from internal parts of the build. GE successfully re-designed the plenum in order to allow for the powder associated with the EBM process to be removed and ORNL printed the full scale plenum of the new design in the Arcam A2X machine. GE fabricated and tested both tensile and low cycle fatigue samples fabricated from $\mathrm{CoCr}$ in the EBM process. Both tensile testing at room temperature and $1000 \mathrm{~F}$ showed consistent results in terms of mechanical properties. It was demonstrated that the tensile properties of $\mathrm{CoCr}$ material fabricated via EBM met the ASTM F75-12 standard for casting alloys. However, the mechanical properties of the EBM material were inferior to materials fabricated using laser based powder systems. Additional work related to process parameter optimization could improve the material properties.

The project also demonstrated the ability to fabricate complex turbine components from Inconel 718 materials using electron beam powder bed deposition (EBM). Bulk samples for tensile testing were fabricated with varied build parameters and orientations, and various thin walled turbine components were fabricated including a spoolie, a swirler, and a sub-scale plenum. Bulk materials properties for Inconel 718 met the required tensile properties for the ASTM specification. However, the thin walled tensile geometries fabricated via EBM and subsequently post processed did not meet ASTM specifications for mechanical properties. However, it should be noted that tensile testing was performed using the as-deposited surface finish. It is recommended that similar testing be conducted with a finish in accordance with the American Society for Testing and Materials (ASTM) specification. In addition, only preliminary processing variables were utilized for sample fabrication and post fracture analysis indicated porosity at the interface of the contour and bulk fill are responsible 
for lower mechanical properties. Additionally, post processing using non-standard post processing methods should be explored. Although the preliminary results were non suitable for these components, It is expected that additional research related to material development will produce material comparable to conventionally processed material.

\subsubsection{Cobalt Chrome}

Prior to the start of this project, the maximum size of cobalt chromium components that could be fabricated using the electron beam melting process was $210 \mathrm{~mm}$ in the $\mathrm{x}-\mathrm{y}$ plane by $\sim 300 \mathrm{~mm}$ tall. Many industrial components targeted for additive manufacturing by GE Power and Water require larger build volumes. This project demonstrated the ability to fabricate a full-scale plenum with a size larger than this current maximum $x-y$ area by using the wide build chamber for the Arcam A2X EBM tool, and by varying the processing parameters in order to input proper energy to minimize porosity. By decreasing the layer thickness from 70 microns to 50 microns, enough energy could be input to the powder to fully consolidate the material. GE Power and Water performed an extensive study on the mechanical properties and microstructure as part of this work. It was demonstrated that the tensile properties of $\mathrm{CoCr}$ material fabricated via EBM met the ASTM F75-12 standard for casting alloys.

GE Power \& Water contributed additional testing to this technical collaboration program. Using an Arcam system and the EBM process, GE produced (100) square test bars, 4" long x 0.5" x 0.5"; these were divided into (60) LCF test specimens and (40) tensile specimens using CoCr. The specimens were divided into three build orientations: vertical, horizontal, and 45 degrees. The vertical specimens had 0.1" diameter centered holes built into them with the EBM process. The specimens are shown in Figures 4-5.
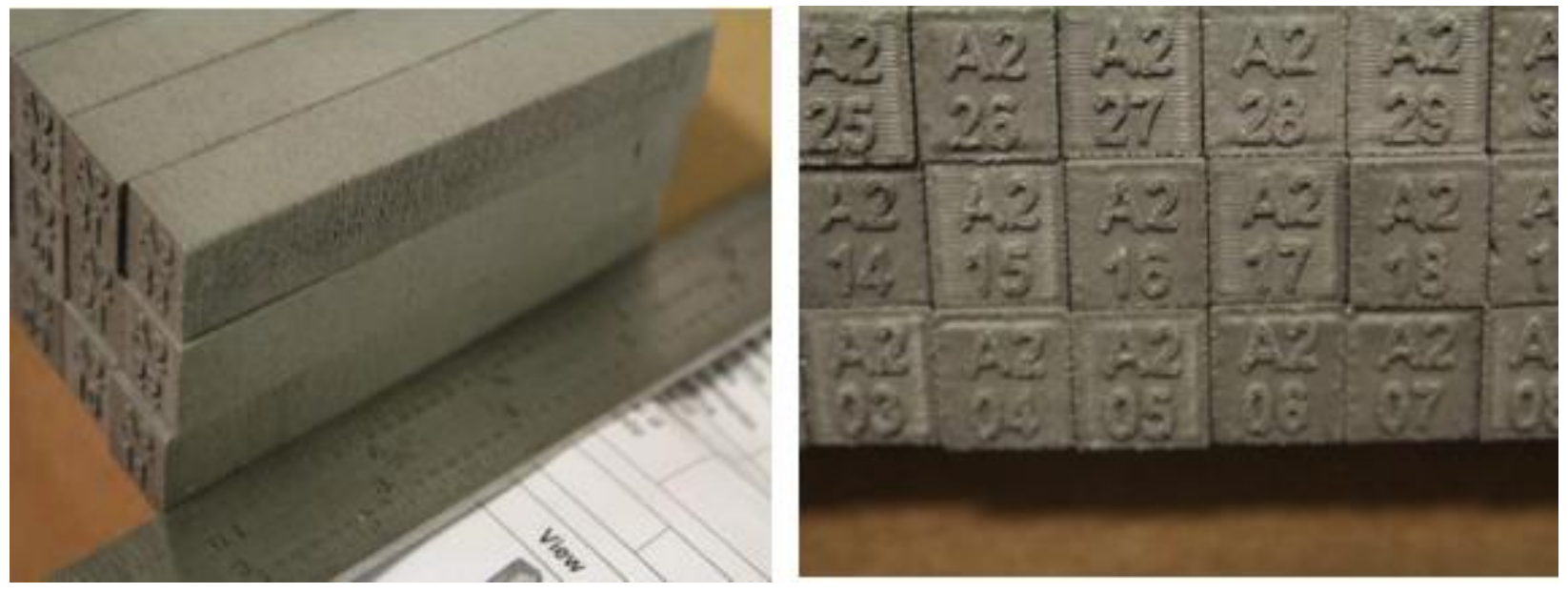

Figure 4. Horizontal LCF/tensile specimens built with EBM. 

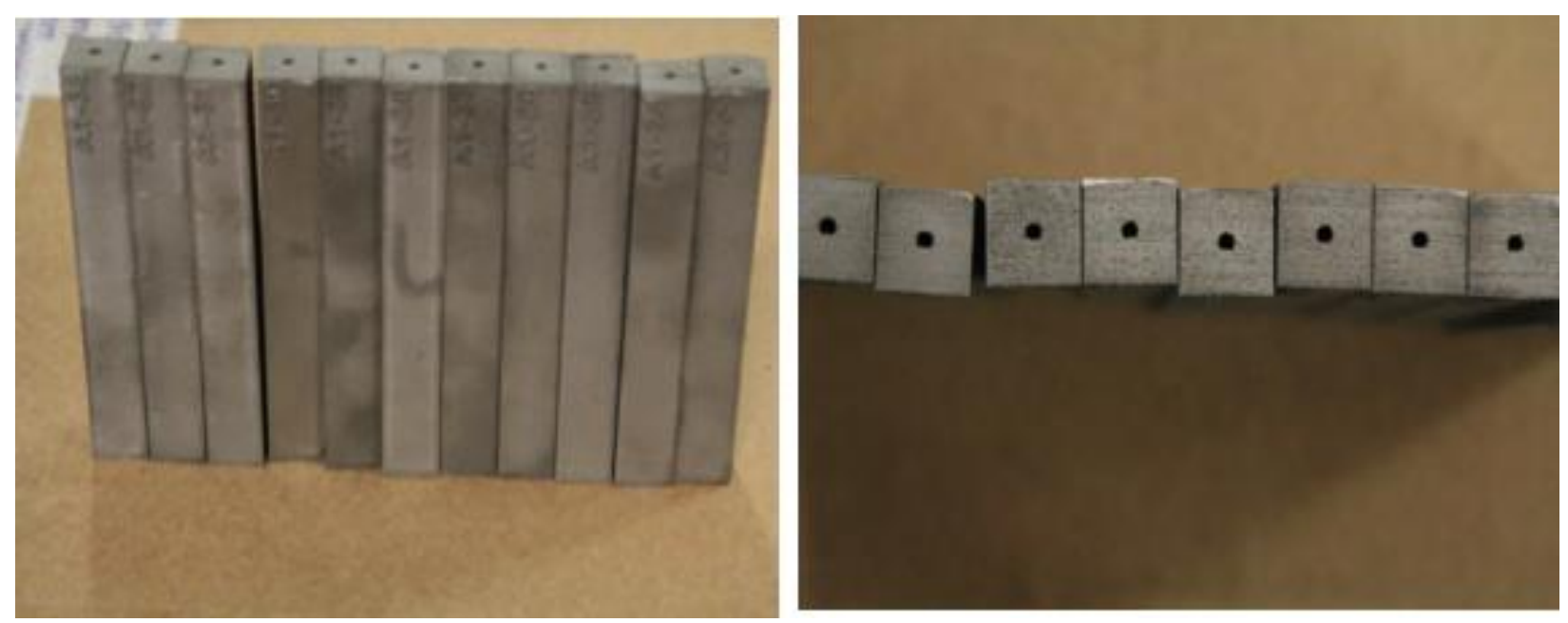

Figure 5. Vertical LCF/tensile specimens built with EBM, with 0.1" center holes built in.

\subsubsection{Surface Finish}

Surface finish of the CoCr EBM test specimens was measured, as it has a direct impact on LCF properties. The results are shown in Table 2 .

Table 2. Surface finish of EBM specimens built in vertical, horizontal and 45 degree orientations

\begin{tabular}{|c|c|c|c|c|c|c|c|c|c|c|c|c|}
\hline & \multicolumn{6}{|c|}{ Top } & \multicolumn{6}{|c|}{ Right } \\
\hline & \multicolumn{3}{|c|}{ Longitudinal } & \multicolumn{3}{|c|}{ Transverse } & \multicolumn{3}{|c|}{ Longitudinal } & \multicolumn{3}{|c|}{ Transverse } \\
\hline & & 2 & 3 & 1 & 2 & 3 & 1 & 2 & 3 & 1 & 2 & 3 \\
\hline Horizontal & 191 & 326 & 218 & 650 & 550 & 500 & 455 & 464 & 477 & 657 & 557 & 693 \\
\hline Vertical & 607 & 520 & 582 & 333 & 344 & 310 & 718 & 656 & 455 & 740 & 782 & 488 \\
\hline 45 Degree & 691 & 698 & 768 & 867 & 743 & 780 & 644 & 725 & 670 & 638 & 589 & 761 \\
\hline
\end{tabular}

\subsubsection{Metallography}

Metallography on the as-built CoCr test specimens revealed that the material was $99.8 \%$ dense (longitudinal) and $99.9 \%$ dense (transverse), indicating minimal porosity was present. These data are comparable to results obtainable with the DMLM (Direct Metal Laser Melting) process.

Microstructures of the CoCr samples are shown in Figures 6-9, as follows: as built (F3); stress relieved (F4); stress relieved + HIP (F5); and stress relieved + HIP + Solution + Age (F6). 


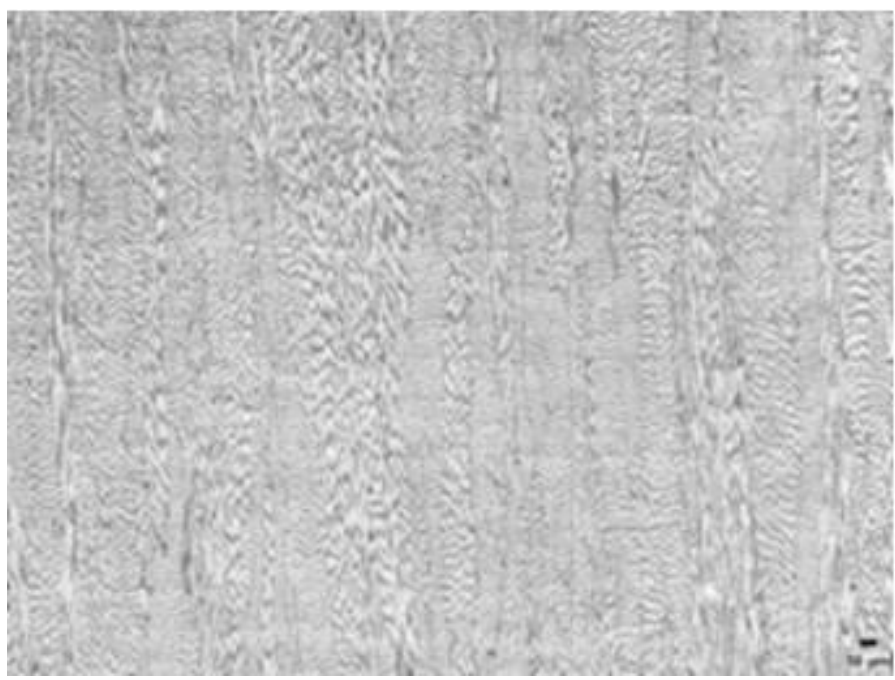

Figure 6. Microstructure of EBM specimens as built.
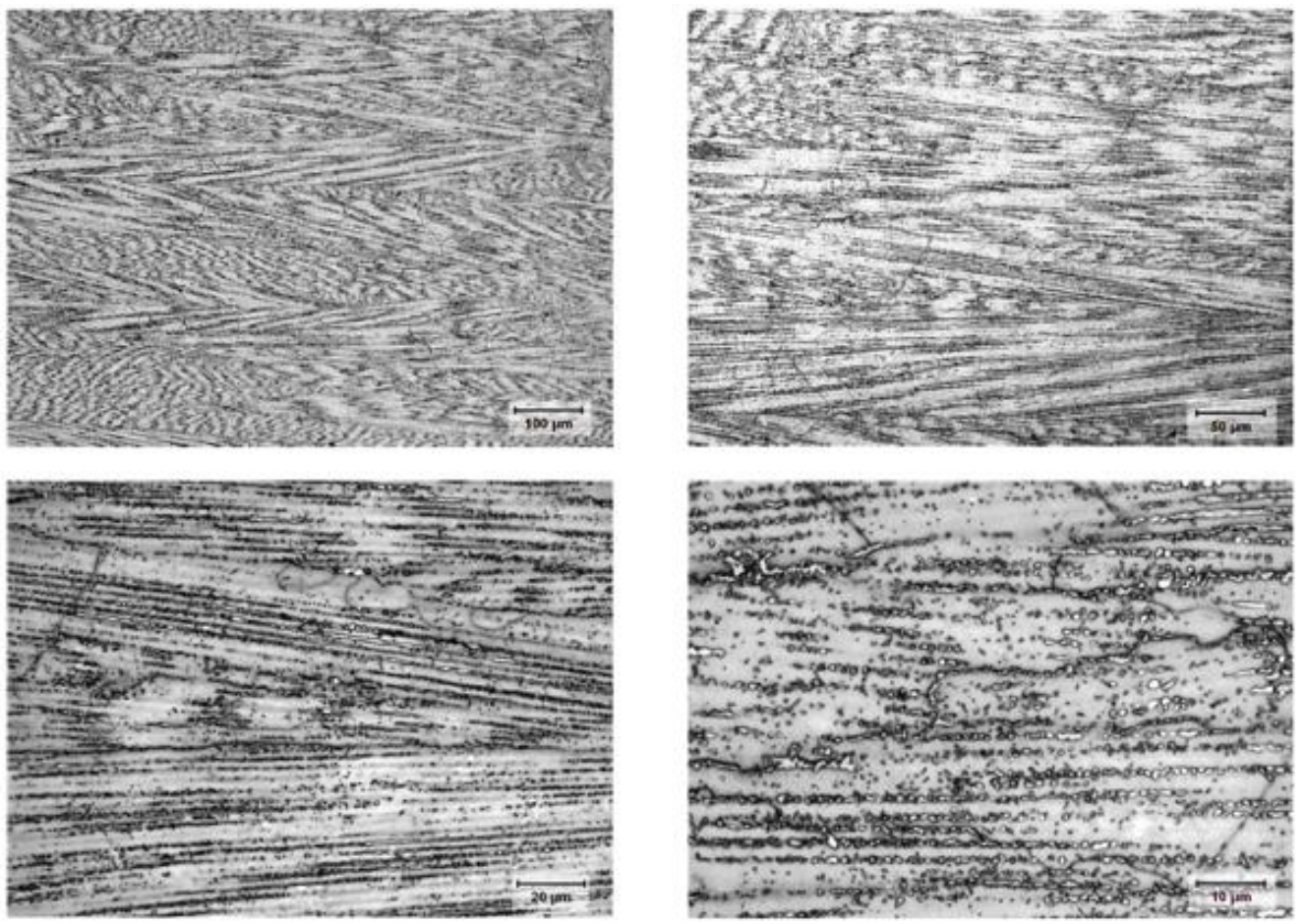

stress relief: $10^{\circ} \mathrm{C} / \mathrm{min}$ to $1052^{\circ} \mathrm{C}$, hold $2 \mathrm{hrs}, \mathrm{cool}$ to $\mathrm{RT}$ at a rate equal to air

Figure 7. Microstructure of EBM specimens as built + stress relieved. 

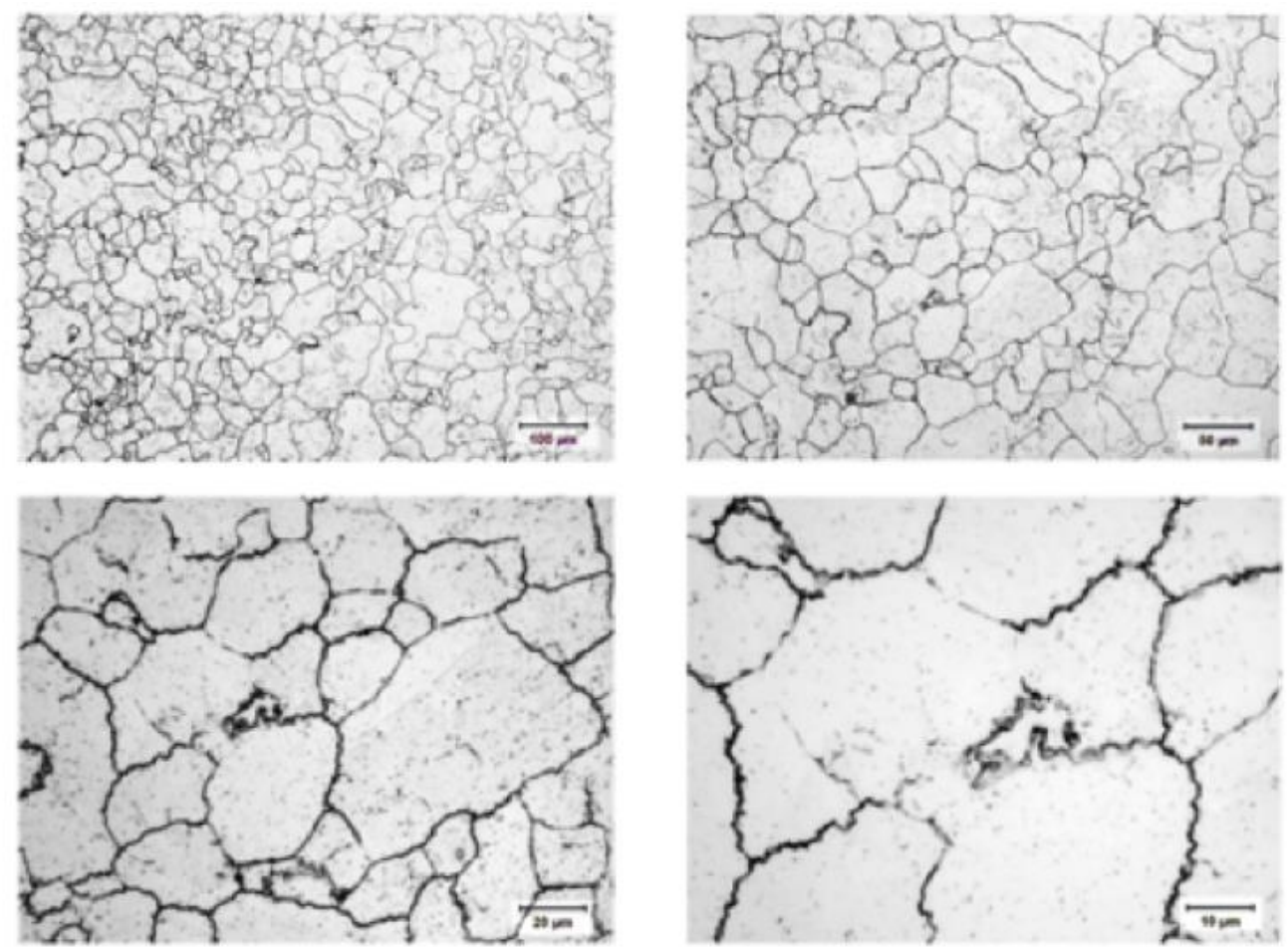

HIP: ramp $10^{\circ} \mathrm{C} / \mathrm{min}$ to $1204^{\circ} \mathrm{C}$, hold $4 \mathrm{hrs}$ at $14.5 \mathrm{ksi}$, furnace cool

Figure 8. Microstructure of EBM specimens as built + stress relieved + HIP'ed.
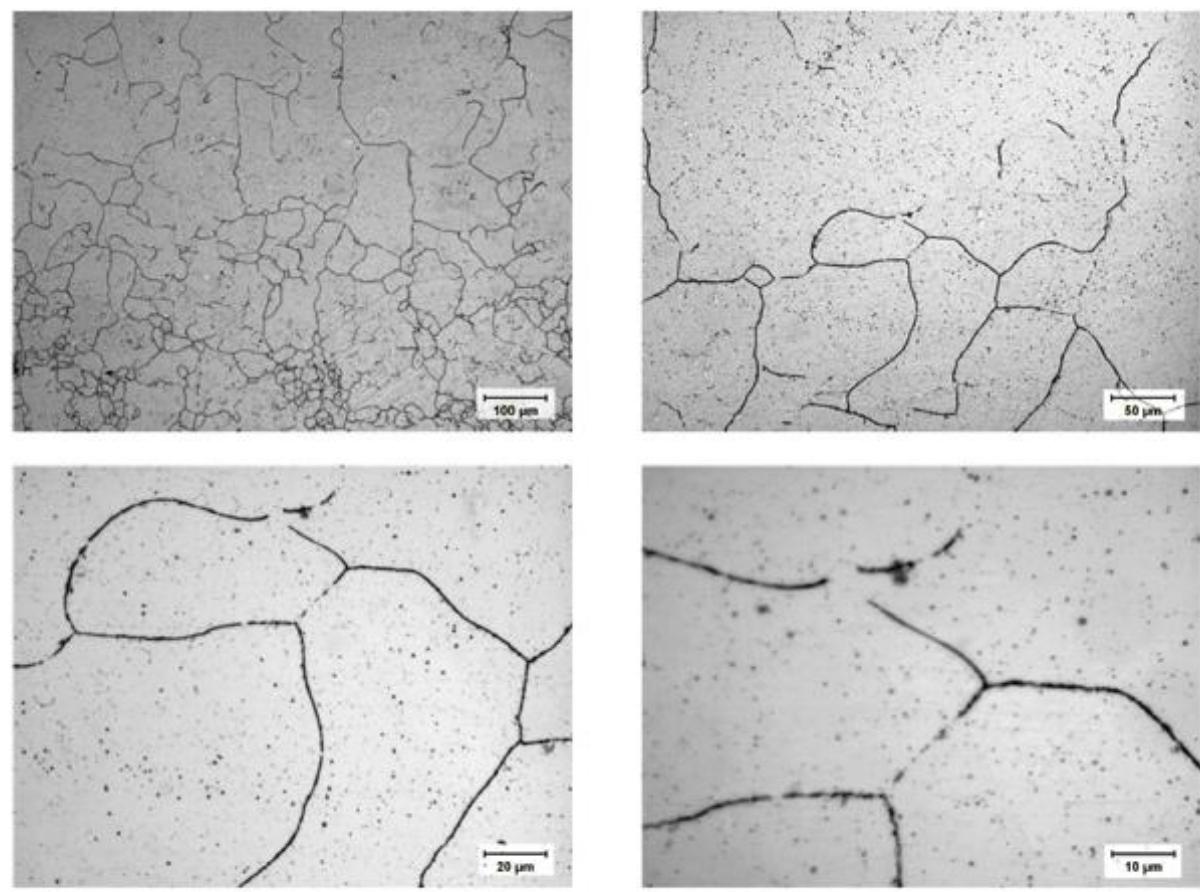

solution: ramp $10^{\circ} \mathrm{C} / \mathrm{min}$ to $1190^{\circ} \mathrm{C}$ in vacuum, cool to $650^{\circ} \mathrm{C}$ within $30 \mathrm{~min}$, cool to $\mathrm{RT}$ at a rate of air cool

Figure 9. Microstructure of EBM specimens as built + stress relieved + HIP'ed + Solution + Age 


\subsubsection{Tensile Testing}

Tensile data are shown in Figure 10 and compared to test results obtained using DMLM on the same CoCr powder. The DMLM results are 20\% higher.

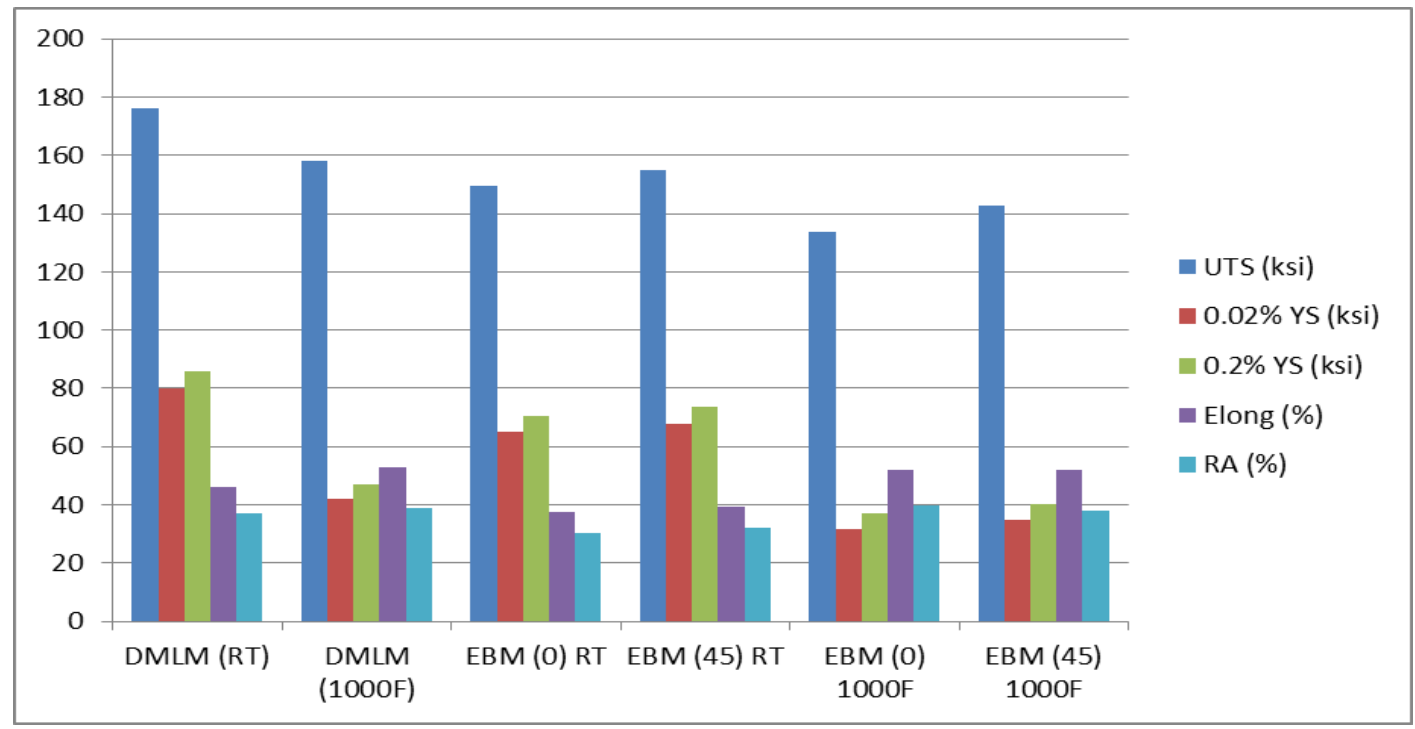

Figure 10. Tensile test results of EBM specimens (stress relieved + HIP'ed + Solution + Age) vs DMLM.

\subsubsection{Life Cycle Fatigue}

Life Cycle Fatigue (LCF) test data are shown in Figure 11 for the CoCr EBM test bars, with and without surface finishing by EDM. Point \#11 is an outlier and should be disregarded. The EDM finish did not produce the expected improvement in properties.

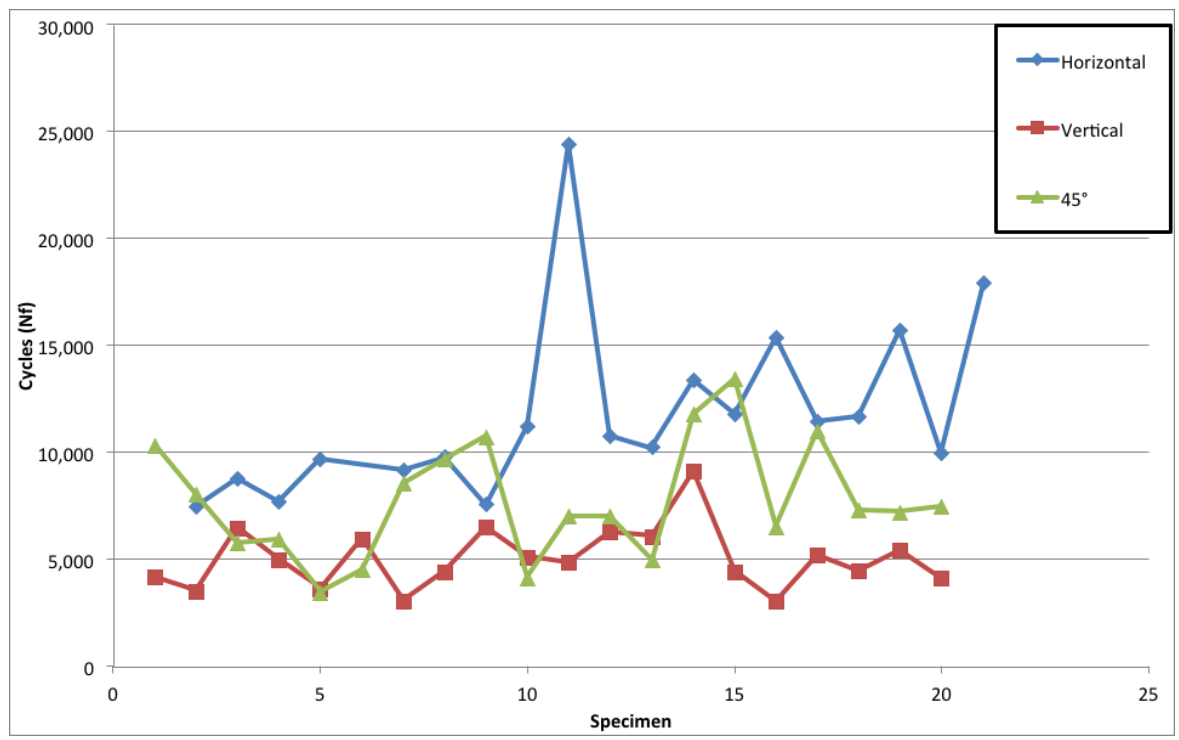

Figure 11. LCF test results of EBM specimens (stress relieved + HIP'ed + Solution + Age) in 3 orientations. Test parameters were: $A=1, f=20 \mathrm{cpm}, R / O=100,000, T=1000 \mathrm{~F}$. 


\subsubsection{Inconel 718}

In addition to CoCr, Inconel 718 is a desirable material for fabrication via EBM because of its wide range of high temperature applications and is costly to fabricate components by traditional manufacturing methods. A second objective of this collaborative research with GE was to evaluate the feasibility of making thin wall components with Inconel 718 using Arcam electron beam powder melting (EBM) process. ORNL demonstrated various components could be fabricated from Inconel 718 with processing parameters currently under development at the MDF. Components printed by ORNL include a spoolie, a swirler, and a reduced scale plenum. Two thin wall tensile geometry layouts were fabricated using similar processing parameters to understand the microstructure and tensile behavior of material fabricated via EBM. Samples were post processed using conventional ASTM specifications for Inconel 718 material including hot isostatic press at 2125F, $14.75 \mathrm{ksi}$ for 4 hours (cooled in an autoclave to 1148F). After HIP, a two step solution anneal was performed per AMS 5662.

Tensile test samples (dog-bone geometry) with three different wall thicknesses (1/8", 1/16" and $1 / 32$ ") were produced. These samples were produced in two separate batches. The Arcam EBM process parameters were varied for these two builds. The EBM samples were subjected to Hot Isotactic Pressing (HIP), and then solution annealed, and aged. The HIP process was conducted at $2125^{\circ} \mathrm{F}$ and $14.75 \mathrm{KSI}$ for 4 hours, followed by cooling in an autoclave to $1148^{\circ} \mathrm{F}$. The solution anneal was conducted at $1796^{\circ} \mathrm{F}$ for one hour and then allowed to air cool. The aging treatment started by holding the samples at $1328^{\circ} \mathrm{F}$ for eight hours, furnace cooled to $1148^{\circ} \mathrm{F}$ in two hours, held at $1148^{\circ} \mathrm{F}$ for eight hours, and then allowed to air cool. The above post-process heat treatments were used to minimize internal discontinuities such as porosity, which are commonly found in thin-walled samples processed by Arcam EBM process. HIP will only help eliminate closed porosity; any porosity that is open to the surface will remain open. Unfortunately, the HIP or heat-treating processes were not done in an inert environment. As a result the surfaces, exposed to ambient environment, were oxidized. For example, Figure 12 shows an oxide layer on the outer surface, including an exposed discontinuity in the surface contour.

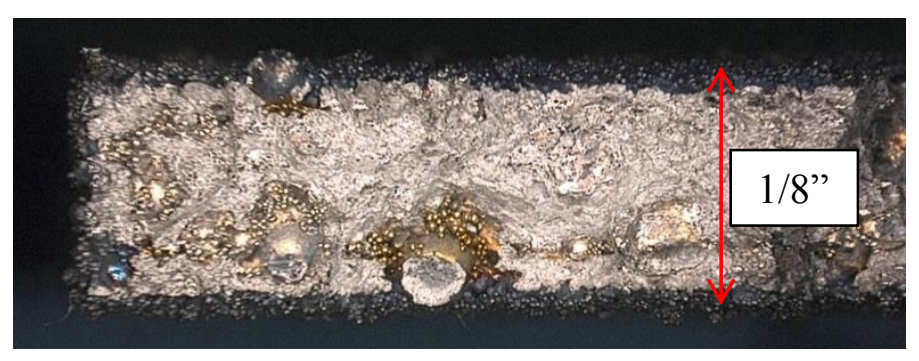

Figure 12. Oxidation can be seen on both the outer surface as well as a cavity that was exposed to the atmosphere during the HIP process.

The contour melted region is responsible for the surface roughness of the finished part, which was qualitatively high for the parts produced during this collaboration. Recent developments in powder quality and process parameter optimization at ORNL have improved surface roughness beyond that shown in this work. As seen in Figure 10, the contour paths show signs of incomplete melting within the sample. This is an artifact of the process parameters. When the contour spot size is not optimized to the contour offset, there is the possibility that there may be areas with lack of fusion. In Figures 9 and 10 it can be seen that there are areas where the powder was not completely melted along the contour paths. Figures 12 and 13 both show the partially melted powder in the contour area at higher 
magnification. By optimizing the contour melt, new thin-wall tests would be expected to exhibit higher yield stresses due to a smoother surface with inherently fewer stress concentrations.

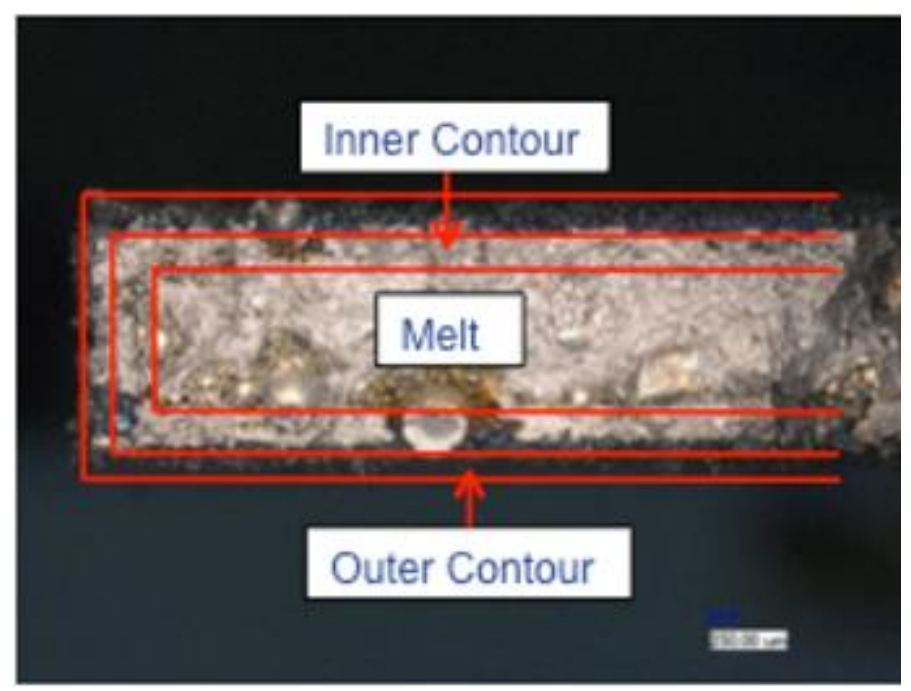

Figure 13. Lines drawn on the boundaries of the inner and outer contours for Sample V2 from 9/05/2013 of $1 / 8$ inch from $30 X$.

\subsubsection{Tensile Testing}

The Inconel 718 samples built in the vertical direction appeared to demonstrate 2 to 5 KSI lower yield strength than the samples that were built in the horizontal direction. This is contradictory with what is expected from thick wall specimens. In a thick wall specimen, epitaxial columnar grain growth should result in superior Z-axis tensile properties. The superior tensile properties in the Z-axis direction are due to pulling parallel to the columnar grains. Pulling on the X-Y plane results in pulling perpendicular to the columnar grains, and results in lower yield stress and elongation. The fact that the thin wall specimen results do not follow the expected trend means that there must be another dominant material mechanism leading to the different failure behavior. The unexpected result of weaker tensile properties in the vertical orientation (Z-axis) can be explained by the contour failure mechanism. The cross sectional area in the gauge section for the thin wall vertical specimens was entirely generated using the contour melt. The surface area in the gauge section for the horizontal specimens was generated partially by the interior melt. The $1 / 32$ " samples exhibit reduced properties in both vertical and horizontal orientation because the gauge section is almost entirely made with the contour melt. Further refinement of the contour melt process should greatly increase the reliability of thin wall parts produced in the Arcam EBM tools. This mechanism, described here as "contour nucleation", requires further study.

The samples were subjected to mechanical testing and the data can be seen below in Figures 1419. The data was arranged by wall thickness and build orientation. Figure 14 shows that the horizontal 1/32" samples that were produced in batch 2 perform better than those produced in batch 1 . Figure 15 shows that in the vertical direction there is no discernable differences in mechanical properties produced by process parameters. In Figures 16 and 17 the results from the 1/16" samples can be seen. For these samples there is also no discernable differences in mechanical properties produced by process parameters for both the horizontal and vertical builds. It can be seen in Figure 17 that many of the samples failed prematurely. This can primarily be attributed to errors in testing. In Figure 18, the horizontal 1/8" samples show little variation and were the most consistent, with little 
effect by process parameters. Figure 19 shows the $1 / 8$ " vertical samples and a clear difference in mechanical properties produced by process parameters. The samples produced in batch 1 performed better than those produced in batch 2. This shows that the Arcam EBM process parameters that work well on thicker samples may not be optimal for thin wall samples. In addition, other factors might have reduced the mechanical properties of the sample. An as-built porosity study conducted by GE revealed that the parameters for batch 2 build produce significantly more porosity. The porosity was measured at the top, middle, and bottom of the sample. No porosity data was provided after HIP and heat treatment.

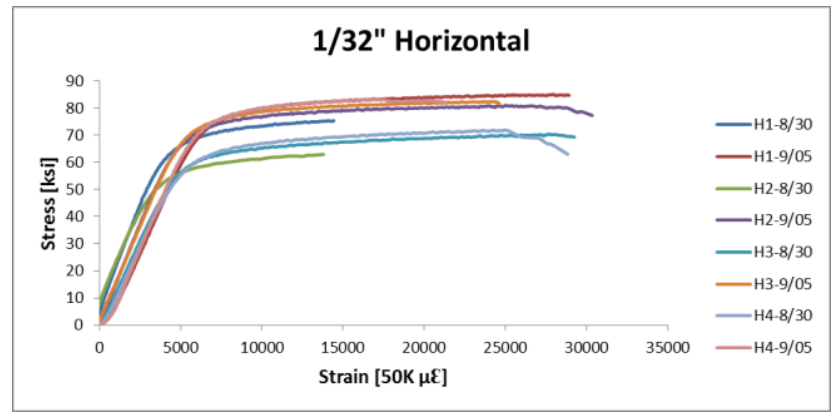

Figure 14. 1/32" Horizontal tensile test results.

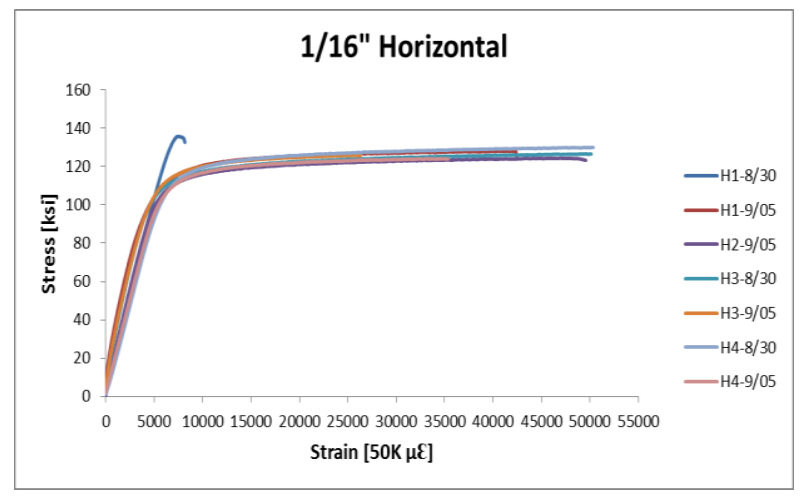

Figure 16. 1/16" Horizontal tensile test results.

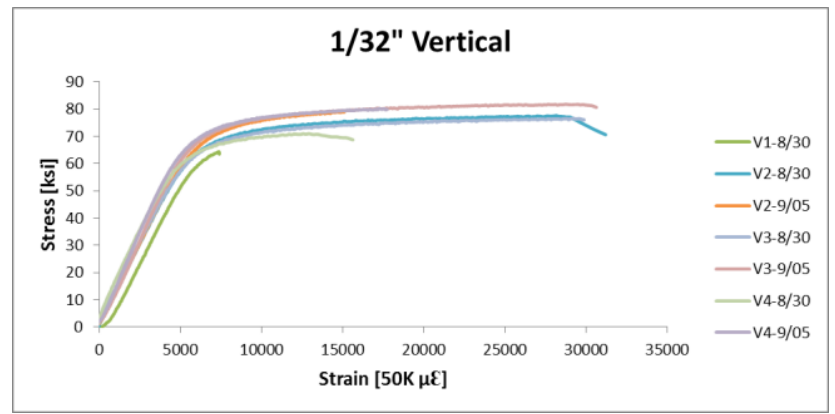

Figure 15. 1/32" Vertical tensile test results.

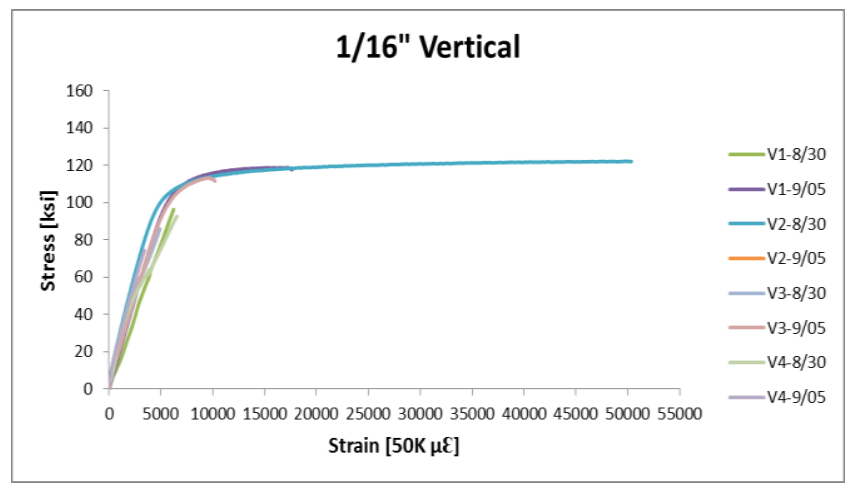

Figure 17. 1/16" Vertical tensile test results. 


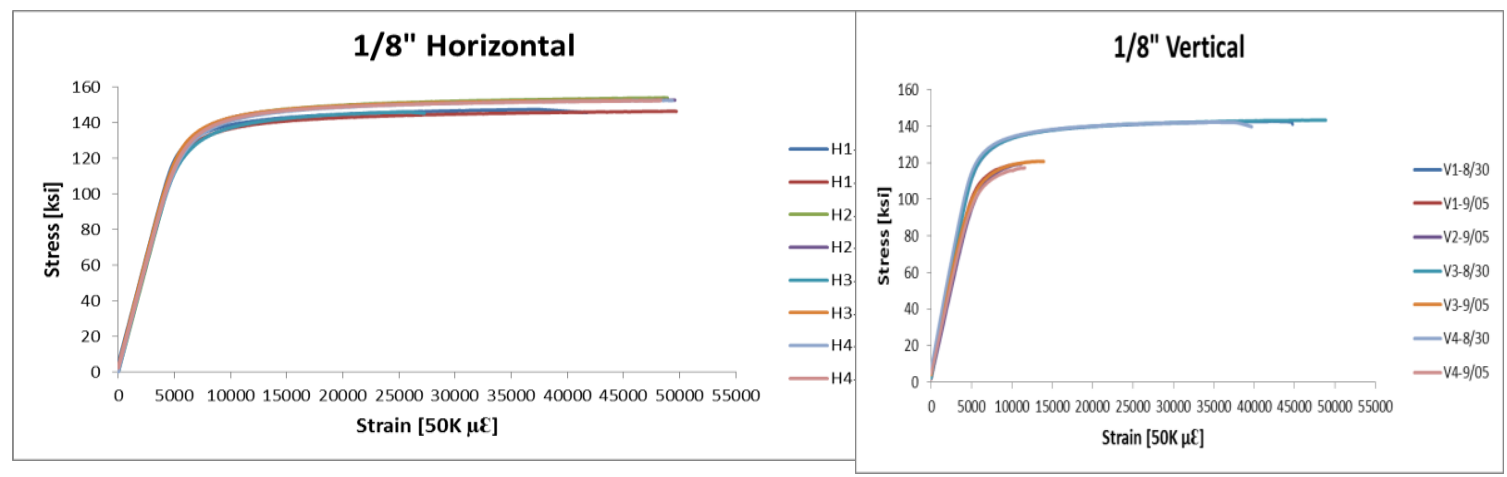

Figure 18. 1/8” Horizontal tensile test results.

Figure 19. 1/8" Vertical tensile test results.
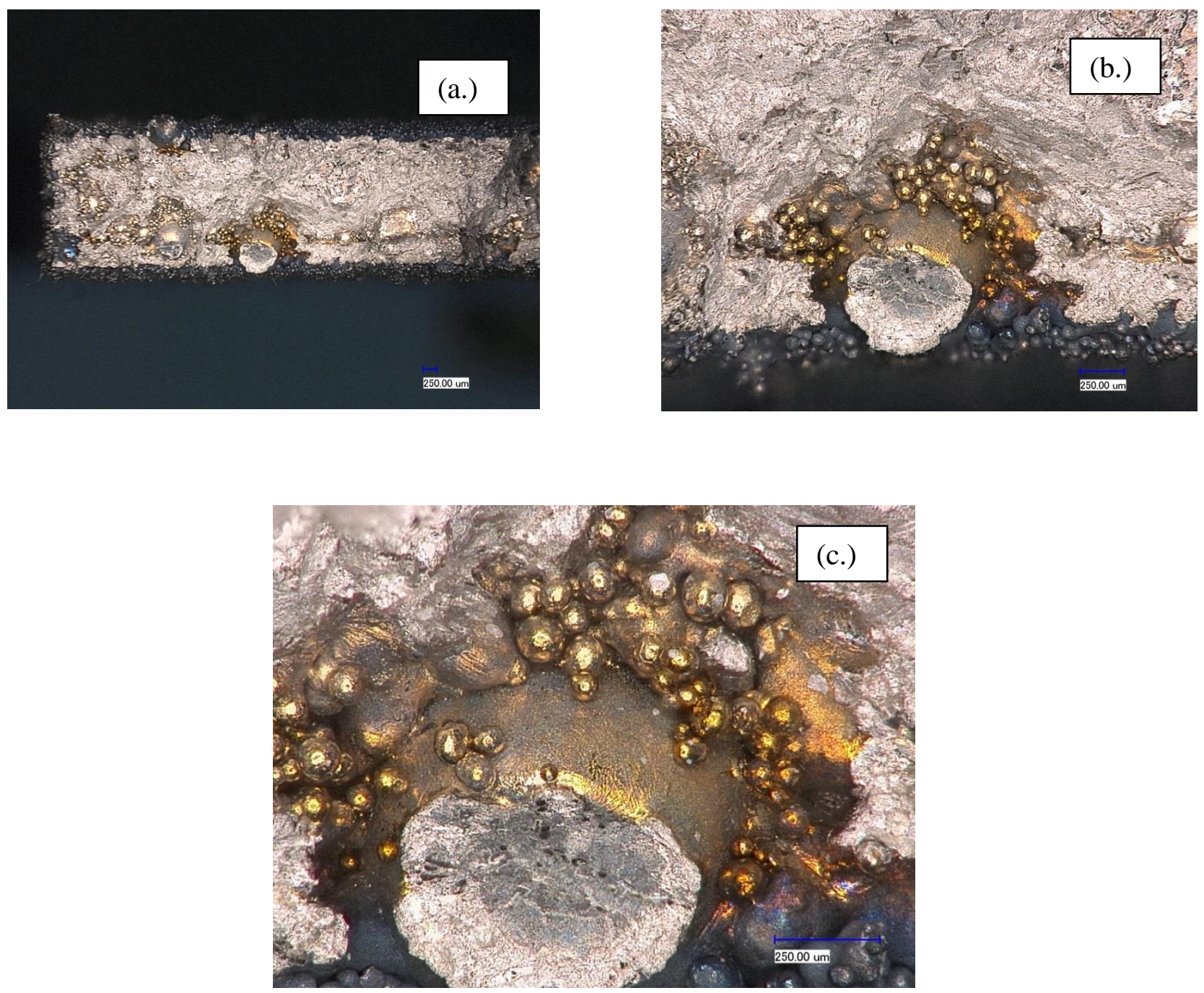

Figure 20. Optical images of sample V2 from batch 2 of 1/8 inch from (a) 30X, (b) 100X, and (c) 200X. These images show interconnected porosity that was open to the surface during HIP and heat treatment. 

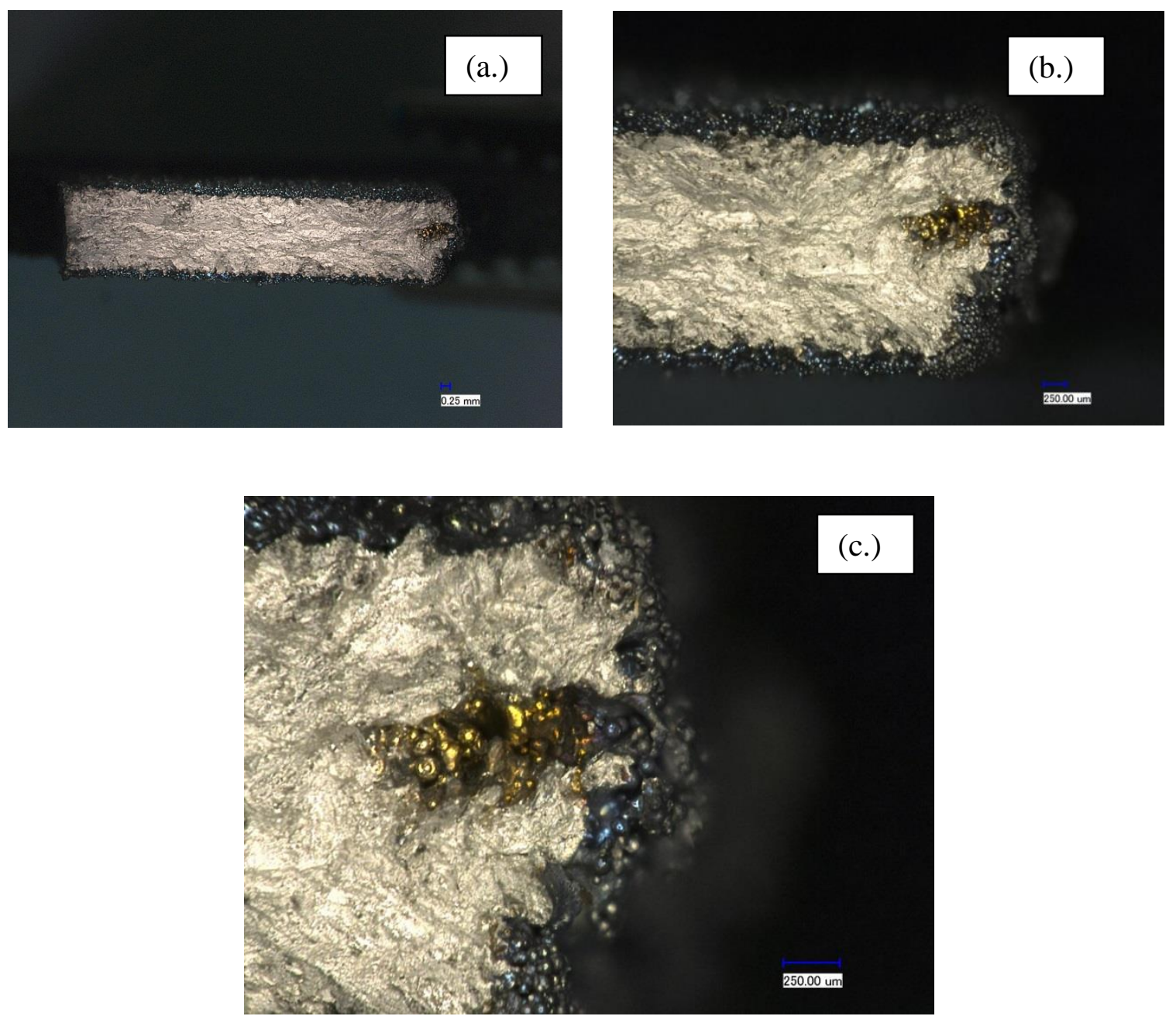

Figure 21. Optical images of Sample $\mathrm{H} 4$ from batch 1 of 1/8 inch from (a) 20X, (b) 50X, and (c) 100X. Another example of interconnected porosity that was open to the surface.

\section{$2.3 \quad$ IMPACTS}

It was demonstrated that a full-scale CoCr plenum could be fabricated using the Arcam EBM technology by variation in the processing parameters. By changing the design of the plenum by GE Power and Water, it was determined that the majority of the powder could be removed from the plenum. Although the tensile data of EBM specimens was $\sim 20 \%$ lower than those obtained using the DMLM process for $\mathrm{CoCr}$ and the low cycle fatigue properties were lower than expected, attributed to surface roughness, internal pores, and lack of fusion, the mechanical properties were repeatable within the test matrix. This has allowed GE Power and Water to have two alternative additive manufacturing technologies that could be utilized to manufacturing plenum components. This is of critical importance for production scale fabrication of components, as having a sole source for component production is not desirable.

It was demonstrated that complex thin walled components could be fabricated from Inconel 718 in an Arcam EBM system. However, it was demonstrated that thin walled components did not match the bulk material properties determined in previous work. The deviation in mechanical properties was related to lack of sample surface adherence to the ASTM specification for mechanical testing (the sample surface was not altered from the as-deposited condition). In addition, the processing 
parameters may need further optimization in order to eliminate porosity between the contour and melting area. However, the results of the work indicate the EBM process has potential to fabricate complex geometries from nickel base superalloy materials.

\subsection{CONCLUSIONS}

It was demonstrated that EBM has the potential to produce complex geometries of interest to GE in both Inconel 718 and $\mathrm{CoCr}$ material. Although the mechanical properties of fabricated materials in this study were relatively consistent, they were not on par with conventionally fabricated and DLMS material. Therefore, additional work must be conducted to 1) optimize the material feedstock for the EBM process, 2) optimize the processing parameters to minimize macro defects and optimize microstructure, and 3) determine ideal post processing and heat treatment for these materials.

Based on the mechanical testing of Inconel 718 material, several conclusions can be drawn. Thin wall samples fabricated by EBM of Inconel 718 exhibit behavior that is unexpected based on traditional thick wall samples; the $\mathrm{X}-\mathrm{Y}$ axis displays slightly better yield strengths than were found in the $\mathrm{Z}$ axis. In addition, the process parameters influenced the thinner samples in a different way than the thicker samples. For the $1 / 32$ " horizontal samples the differing parameters led to different yield strengths were as the 1/32" vertical samples showed no influence due to parameter change. The 1/16' samples showed no influence due to build direction or process parameter. In the thicker $1 / 8$ " samples, the horizontal samples showed no changes due to process parameters, but the vertical samples showed a clear difference.

The impact of contour nucleation in Inconel 718 parts on as-built part failure requires further study. Additional work would explore the use of improved powder feedstock, varying contour spacing, and varying contour melt current and beam speed. Improvements in surface finish from recent runs with a new powder feedstock warrant a re-run of the mechanical tests performed in this study.

For the case of CoCr materials, the mechanical properties in both tensile and LCF were repeatable. However, the properties were lower than through the fabrication using laser powder bed manufacturing. Therefore, a more detailed investigation into the relationship between processing parameters, microstructure, and mechanical properties is required.

As built porosity in thicker CoCr sections ( 0.5 " x 0.5 " test bars) was quite normal, but the surface roughness was relatively coarse. Smoothing the surface via post-build processing could potentially produce improved LCF results, and this should be investigated further. EDM processing did not have a positive impact on the surface.

Overall, the production of several GE parts via EBM was very encouraging, especially in the light of improved sintered powder removal from internal portions of the plenum via a relatively simple design modification. GE continues to investigate EBM, DMLM, and other Additive Manufacturing technologies to facilitate more innovative and efficient part designs, rapid prototyping, and implementation into production of AM parts in the near future.

GE and ORNL are discussing entering a second phase of this collaborative program, to include: development of EBM on several materials (stainless steels, super-alloys, Co-based alloys, etc.) and characterizing their properties; optimization of EBM parameters to improve properties, quality, cycle times, distortion; investigating the next generation of Arcam equipment to assess process improvements; real-time inspection tools during the EBM process to reduce or eliminate post-build 
inspection requirements and identify flawed builds as they occur; development of process maps correlating parameters to quality, distortion, and residual stresses.

This program established the groundwork for such development efforts, and GE will continue to support such technical collaborations to maximize the benefits to all parties involved in the effort. 


\section{PARTNER BACKGROUND}

GE \{NYSE: GE $\}$ is an American multinational conglomerate corporation incorporated in Schenectady, New York, and headquartered in Fairfield, Connecticut. GE's divisions include GE Capital, GE Power \& Water, GE Oil \& Gas, GE Aviation, GE Healthcare, GE Transportation, and GE Home \& Business Solutions. The company is one of the largest in the United States and has over 300,000 employees.

GE Power \& Water is an international leader in energy products and services, serving power generation, industrial, marine, oil and gas, and distributed generation markets. As a major gas turbine OEM, GE Power \& Water offers unique industry specific engineering and customer facing application insights and experience to drive clean energy technology commercialization at meaningful scale.

GE Power \& Water is the world's leading supplier of Industrial Gas Turbine engines with over 5,000 gas turbines installed worldwide, and has a demonstrated track record of developing and commercially implementing advanced materials technologies. 